\title{
Frequency of Use of Fixed-Combination Eye Drops by Patients with Glaucoma at Multiple Private Practices in Japan
}

\author{
Kenji Inoue', Ryoko Komori', Shiho Kunimatsu-Sanuki ${ }^{2}$, Kyoko Ishida $\mathbb{D}^{3}$, Goji Tomita $\mathbb{D}^{1,3}$ \\ 'Inouye Eye Hospital, Tokyo, Japan; ${ }^{2}$ Nishikasai Inouye Eye Hospital, Tokyo, Japan; ${ }^{3}$ Department of Ophthalmology, Toho University Ohashi Medical \\ Center, Tokyo, Japan
}

Correspondence: Kenji Inoue, Inouye Eye Hospital, 4-3 Kanda-surugadai, Chiyoda-ku, Tokyo, I0I-0062, Japan, Tel +8I3-3295-09II, Fax +8I3-3295-09I7, Email 2inoue-k@inouye-eye.or.jp

\begin{abstract}
Purpose: To investigate the current use of fixed-combination eye drops by patients with glaucoma in Japan.
Patients and Methods: A total of 5303 outpatients (5303 eyes) with glaucoma or ocular hypertension were enrolled in the survey at 78 private practices from March 8 to 14, 2020. The medications they used were investigated. The use of fixed-combination medications was analyzed, stratified by the number of medications used. The results were compared to those of the survey performed in 2016 via $\chi^{2}$ tests.

Results: Fixed-combination medications were used by $55.6 \%, 79.8 \%, 84.9 \%, 91.3 \%$, and $94.1 \%$ of patients in the two-, three-, four-, five, and six-medications groups. The use of prostaglandin analog/ $\beta$-blocker $(\mathrm{PG} / \beta)$, carbonic anhydrase inhibitor $/ \beta$-blocker $(\mathrm{CAI} / \beta)$, and $\alpha$-2-adrenergic agonist/ $\beta$-blocker $(\alpha 2 / \beta)$ fixed-combination medications were $42.8 \%, 12.0 \%$, and $0.8 \%$ in the two-medications group; $36.2 \%, 41.6 \%$, and $2.0 \%$ in the three-medications group; and $23.5 \%, 60.1 \%$, and $1.3 \%$ in the four-medications group, respectively. The most commonly used fixed-combination medications were $\mathrm{PG} / \beta$ in the two-medications group and $\mathrm{CAI} / \beta$ in the groups using three or more medications. Compared to those in the survey performed in 2016 , there were increases (both $\mathrm{P}<0.0001)$ in the use of $\mathrm{PG} / \beta$ fixed-combination medication in the two- $(28.7 \%$ to $42.8 \%)$ and three-medications $(21.7 \%$ to $36.2 \%)$ groups, and none in the use of $\mathrm{CAI} / \beta$ fixed-combination medication. There was little use of $\alpha 2 / \beta$ fixed-combination medication, probably because it was launched only three months before the survey.
\end{abstract}

Conclusion: The proportion of fixed-combination medications increased as the number of medications per patient increased.

Keywords: intraocular pressure, $\mathrm{PG} / \beta$ fixed combination, $\mathrm{CAI} / \beta$ fixed combination, $\alpha 2 / \beta$ fixed combination, multicenter

\section{Introduction}

In the treatment of glaucoma, it is important to maintain and improve patient adherence to medication. ${ }^{1}$ Adherence is liable to be lower with multidrug combination therapy than with monotherapy because of the higher number of medications, instillations, and possible adverse reactions. ${ }^{2}$ Therefore, fixed-combination eye drops were developed to improve adherence when multiple drugs are required. In Japan, the following fixed-combination medications have been introduced: latanoprost/timolol, travoprost/timolol, and dorzolamide/timolol, in 2010; brinzolamide/timolol, in 2013; and tafluprost/timolol, in 2014. We are interested in the actual status of treatment for glaucoma patients and have been conducting a multi-institutional survey of glaucoma every 3 to 4 years since $2007 .{ }^{3}$ Since the institutions involved in the surveys consist of private practitioners located all over Japan, we believe that the results obtained from the surveys reflect the real-world status of medical treatment for glaucoma in Japan. We conducted the fourth survey in $2016,{ }^{4}$ for which we reported separately on the use of fixed-combination eye drops. ${ }^{5}$ Therein, we observed an increase in the use of fixedcombination eye drops compared to the third survey, conducted in $2012 .{ }^{6}$ After the survey in 2016, further fixedcombination eye drops became available in Japan: latanoprost/carteolol, in 2017 and brimonidine/timolol, in 2019. The launch of latanoprost/carteolol fixed-combination eye drops marked the first time that a drug other than timolol was used 
as $\beta$-blocker in such medication in Japan. These new developments may have changed the use of fixed-combination eye drops in Japan. Therefore, we conducted the fifth survey ${ }^{7}$ in 2020 by using the same questionnaire as for past surveys, with the addition of the names of the new drugs that had become available (Figure 1). Knowledge of the current status of use of fixed-combination eye drops is important. As mentioned earlier, the use of fixed-combination eye drops possibly improves patients' adherence to the medication, which may increase the success of medical treatment for glaucoma. The use of fixed-combination eye drops may also reduce adverse reactions by reducing patients' exposure to preservatives and reducing the risk of contact with the eye-drop bottle. If it can be determined which fixed-combination eye drops are widely used, and in which situations, clinical practice may be improved and new fixed-combination eye drops may be developed with cooperation between the pharmaceutical industry and academia in future.

Our aim in this study was to analyze the use of fixed-combination eye drops from data obtained in the fifth survey. We also aimed to compare these results with those of the 2016 survey, ${ }^{5}$ to investigate changes over time.

\section{Materials and Methods}

We asked those institutions employing ophthalmologists who have worked in the Inoue Eye Hospital Group in the past, as well as institutions that collaborate with our hospital on a medical level to cooperate in the survey. The survey was conducted at 78 participating institutions that agreed to cooperate (Table 1) from March 8 to 14, 2020. All outpatients with glaucoma or ocular hypertension during the study period were included. The total number of patients was 5303 (one eye each). The diagnosis of and treatment for glaucoma were performed at the discretion of the attending physician in accordance with the 2018 guidelines for the clinical management of glaucoma. ${ }^{1}$ The investigation included the affected eye of patients with unilateral glaucoma or ocular hypertension, and the right eye of patients with bilateral disease. The

The $5^{\text {th }}$ Survey for Glaucoma

\begin{tabular}{|c|c|c|c|c|}
\hline Initials & & & Patient number & \\
\hline Sex & M: Male & - F: Female & Age & years \\
\hline Diagnosis & $R \cdot L$ & \multicolumn{3}{|c|}{$\begin{array}{l}\text { 1: POAG 2:NTG } \quad 3: \text { PACG } \\
\text { 4: Secondary glaucoma (including exfoliation glaucoma) } \\
\text { 5: Ocular hypertension } \quad 6: \text { Infantile glaucoma }\end{array}$} \\
\hline \multirow{2}{*}{$\begin{array}{l}\text { History of } \\
\text { surgery }\end{array}$} & $1:$ No & & & \\
\hline & 2: Yes & \multicolumn{3}{|c|}{$\begin{array}{l}\text { 1: Trabeculectomy 2: Trabeculotomy } 3: \text { Goniosynechialysis } \\
\text { 4: Tube-shunt } 5: \text { Others }(\end{array}$} \\
\hline \multirow{2}{*}{$\begin{array}{l}\text { History of } \\
\text { laser }\end{array}$} & $1:$ No & & & \\
\hline & $2:$ Yes & \multicolumn{3}{|c|}{ 1: LI $\quad$ 2: SLT (ALT) 3: Others ( } \\
\hline \multirow{5}{*}{$\begin{array}{l}\text { Prescription } \\
\quad \text { drug }\end{array}$} & $1:$ No & \multicolumn{3}{|c|}{ 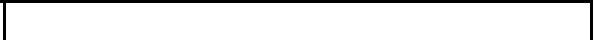 } \\
\hline & \multirow{4}{*}{$2:$ Yes } & \multicolumn{3}{|c|}{ 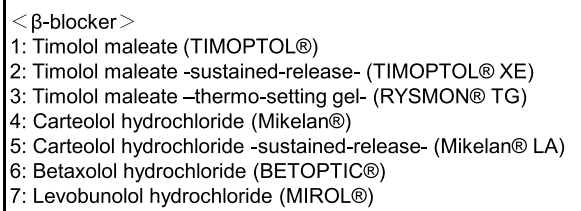 } \\
\hline & & \multicolumn{3}{|c|}{$\begin{array}{l}\text { <aß-blocker }> \\
\text { 8: Nipradilol (HYPADIL) }\end{array}$} \\
\hline & & \multicolumn{3}{|c|}{$\begin{array}{l}\text { <lon channel> } \\
\text { 9: Isopropyl unoprostone (Rescula®) } \\
\text { <PG analogs }> \\
\text { 10: Latanoprost (Xalatan } ®) \\
\text { 11: Travoprost (TRAVATANZ®) } \\
\text { 12: Tafluprost (TAPROS®) } \\
\text { 13: Bimatoprost (LUMIGAN®) }\end{array}$} \\
\hline & & \multicolumn{3}{|c|}{$\begin{array}{l}<P G+\beta \text {-blocker fixed combination }> \\
\text { 14: Latanoprost/timolol fixed combination (Xalacom®) } \\
\text { 15: Travoprost/timolol fixed combination (DUOTRAV®) } \\
\text { 16: Tafluprost/timolol fixed combination (TAPCOM } 囚 \text { ) } \\
\text { 17: Latanoprost/carteolol fixed combination (Mikeluna } ₫ \text { ) }\end{array}$} \\
\hline
\end{tabular}

\begin{tabular}{|c|c|c|}
\hline \multirow{8}{*}{$\begin{array}{l}\text { Prescription } \\
\text { drug }\end{array}$} & \multirow{8}{*}{$2:$ Yes } & $\begin{array}{l}<\text { CAl+ } \beta \text {-blocker fixed combination }> \\
\text { 18: Dorzolamide/timolol fixed combination (COSOPT®) } \\
\text { 19: Brinzolamide/timolol fixed combination (AZORGA })\end{array}$ \\
\hline & & $\begin{array}{l}<\text { CAl eye drop }> \\
\text { 20: Dorzolamide hydrochloride (Trusopt } \Theta \text { ) } \\
\text { 21: Brinzolamide (Azopt } ₫ \text { ) } \\
\text { <Oral CAI }> \\
\text { 22: Acetazolamide (DIAMOX®) }\end{array}$ \\
\hline & & $\begin{array}{l}<\alpha_{1} \text {-antagonist }> \\
\text { 23: Bunazosin hydrochloride (Detantol@) }\end{array}$ \\
\hline & & $\begin{array}{l}<\alpha_{2} \text {-agonist }> \\
\text { 24: Brimonidine tartrate (AIPHAGAN } \otimes \text { ) }\end{array}$ \\
\hline & & $\begin{array}{l}<\text { ROCK inhibitor }> \\
\text { 25: Ripasudil hydrochloride (GLANATEC }()\end{array}$ \\
\hline & & $\begin{array}{l}\text { <EP2 agonist> } \\
\text { 26: Omidenepag isopropyl (EYBELIS } ®)\end{array}$ \\
\hline & & $\begin{array}{l}<\alpha 2 \text {-agonist }+\beta \text {-blocker fixed combination }> \\
\text { 27: Brimonidine/timolol fixed combination (AIBETA®) }\end{array}$ \\
\hline & & $\begin{array}{l}<\text { Others> } \\
\text { 28: Pilocarpine hydrochloride (Sanpilo®) } \\
\text { 29: Dipivefrin hydrochloride (Pivalephrine } ® \text { ) } \\
\text { 30: Others ( ) }\end{array}$ \\
\hline
\end{tabular}

Figure I The questionnaire for the survey.

Abbreviations: $\alpha_{1}$-agonist, $\alpha_{1}$-adrenergic agonist; $\alpha_{2}$-agonist, $\alpha_{2}$-adrenergic agonist; ALT, argon laser trabeculoplasty; CAI, carbonic anhydrase inhibitor; EP2, prostaglandin $\mathrm{E}_{2}$ receptor 2; L, left; LI, laser iridotomy; NTG, normal-tension glaucoma; PACG, primary angle-closure glaucoma; PG, prostaglandin analog; POAG, primary open-angle glaucoma; R, right; ROCK, Rho-associated protein kinase; SLT, selective laser trabeculoplasty. 
Table I The 78 Institutions Participating in the 2020 Survey

\begin{tabular}{|c|c|c|}
\hline Fujita Eye Clinic & Toyama Eye Clinic & Hakuai Kobayashi Eye Clinic \\
\hline Kinukawa Ganka & Oohara Ganka & Saihakuganka Clinics \\
\hline Izumi Eye Clinic & Shinozaki Ekimae Takahashi Ophthalmology Clinic & Kugahara Eye Clinic \\
\hline Sanai Ophthalmology Clinic & Miyazaki Ophthalmology Clinic & Fujiwara Eye Clinic \\
\hline Saiki Eye Clinic & Hashida Eye Clinic & Kawazoe Eye Clinic \\
\hline Ishii Eye Clinic & Soga Eye Clinic & Maki Ophthalmology Clinic \\
\hline Yanagawa Ganka & Takanawadai Eye Clinic & Oharachika Ophthalmology Clinic \\
\hline Fukasaku Ophthalmology & Waseda Ophthalmology Clinic & Kasai Ophthalmology \\
\hline Tajima Eye \& Plastic Clinic & logi Kikuchi Eye Clinic & Horikawa Eye Clinic \\
\hline Aoyagi Eye Clinic & Inage Eye Clinic & Yanase Ophthalmology Clinic \\
\hline Hongo Eye Clinic & Akatsuka Eye Clinic & Matobaganka Clinics \\
\hline Yoshida Eye Clinic & Egi Eye Clinic & Nishikamata Eye Clinic \\
\hline Noda Ganka Masuika lin & Higako Ganka & Ogawa Eye Clinic \\
\hline Miyake Eye Clinic & Goto Eye Clinic & Yoshida Eye Clinic \\
\hline Takanedai Ophthalmology Clinic & Ogawa Eye Clinic & Shirokane Eye Clinic \\
\hline Yatsu Ekimae Ajisai Ophthalmology Clinic & Nishifu Hikari Eye Clinic & Otakibashi Nishino Eye Clinic \\
\hline Oami Eye Clinic & Dannoue Ophthalmology Clinic & Atsumi Clinic (Tokyo) \\
\hline Nakayama Eye Clinic & Tsunashima-Ekimae Eye Clinic & Atsumi Clinic (Kakegawa) \\
\hline Morichika Eye Clinic & Nakai Eye Center & Hayashi Ophthalmology Clinic \\
\hline Nakazawa Eye Clinic & Saito Eye Clinic & Nakamura Ganka Keiseigeka \\
\hline Komagome Mitsui Eye Clinic & Hillside Eye Clinic & Sakura Eye and Internal Medicine Clinic \\
\hline Tachikawa Shindo Eye Clinic & Zushi Eye Clinic & Omiya Inouye Eye Clinic \\
\hline Sugahara Eye Clinic & Imakoga Ophthalmology Clinic & Sapporo Inouye Eye Clinic \\
\hline Ueda Eye Clinic & Murakami Eye Clinic & Nishikasai Inouye Eye Hospital \\
\hline Emoto Eye Clinic & Gakiya Eye Clinic & Ochanomizu Inouye Eye Clinic \\
\hline Ezure Ophthalmology Clinic & Kawashima Eye Clinic & Inouye Eye Hospital \\
\hline
\end{tabular}

right eye was selected because of the multi-center nature of the study, to reduce the burden of randomization on the attending physicians. The study protocol was approved by the Inouye Eye Hospital's ethics committee (approval number: 201606-1) and the study adhered to the tenets of the Declaration of Helsinki. Written informed consent was waived by the committee because of the retrospective study design. The study information was provided to participants by the institutions, and the participants had the opportunity to opt out of the study.

The survey was conducted by using a questionnaire (Figure 1). The questionnaires were sent to each institution in advance. Patient data, including age, sex, diagnosis, number and type of medications in use, and history of laser treatment or surgery for glaucoma at the time of consultation were collected from the medical records. Aggregation was performed at the Inouye Eye Hospital. From these questionnaires, we analyzed the use of fixed-combination eye drops. In addition, the results were compared with those of the 2016 survey. ${ }^{5}$ Specifically, we compared patients who used fixedcombination eye drops (prostaglandin analog/ $\beta$-blocker $[\mathrm{PG} / \beta]$, carbonic anhydrase inhibitor/ $\beta$-blocker $[\mathrm{CAI} / \beta]$, and $\alpha$ 2 -adrenergic agonist $/ \beta$-blocker $[\alpha 2 / \beta]$ ) by dividing them into groups by the number of medications used (one to seven). Fixed-combination eye drops were regarded as two medications.

For historical data, we used results obtained from the fourth survey, performed from March 7 to 13, 2016. ${ }^{5}$ Fiftyseven institutes participated in that survey, including 4288 patients (one eye each).

For statistical analyses, the $\chi^{2}$ and Fisher's exact tests were used for comparisons of glaucoma types and medications, Fisher's exact test was used for comparisons of sex and patient history of surgery and laser treatment, and the MannWhitney $U$-test was used for comparisons of age and number of medications. Yate's continuity correction was used to correct for the $\chi^{2}$ test. All statistical analyses were conducted by using IBM SPSS Statistics for Windows, version 22 (IBM Corp., Armonk, NY, USA). A P-value $<0.05$ was considered statistically significant. 


\section{Results}

\section{Patients}

The patients were 2347 men and 2956 women, and their mean age was $68.7 \pm 13.1$ years (mean \pm standard deviation), ranging from 11 to 101 years (Table 2). The diagnoses were normal-tension glaucoma in 2710 patients, primary openangle glaucoma (POAG) in 1638, secondary glaucoma in 435, ocular hypertension in 286, primary angle-closure glaucoma (PACG) in 225, infantile glaucoma in 4, and others in 5. In terms of ophthalmological history, 366 patients had undergone surgery and 220 had undergone laser treatment. The mean number of medications used was $1.8 \pm 1.3 ; 543$ patients (10.2\%) were using no medication, 2203 (41.5\%) used one, 1217 (22.9\%) used two, 754 (14.2\%) used three, 391 (7.4\%) used four, $160(3.0 \%)$ used five, $34(0.6 \%)$ used six, and $1(0.02 \%)$ used seven.

\section{Use of Fixed-Combination Eye Drops}

Medications used in the two-medication group are shown in Figure 2. Notably, $\alpha 2 / \beta$ fixed-combination eye drops were used by only 10 patients $(0.8 \%)$.

Fixed-combination medications were used by 602 (79.8\%), $332(84.9 \%), 146(91.3 \%)$, and $32(94.1 \%)$ patients in the three-, four-, five-, and six-medications groups, respectively. The details of these groups are shown in Table 3. The patient using seven medications used PG analogs $+\mathrm{CAI} / \beta$ fixed combination (dorzolamide/timolol) $+\mathrm{CAI}$ (oral) + $\alpha 1$-blocker $+\alpha 2$-agonist + Rho-associated protein kinase (ROCK) inhibitor.

\section{Comparison with the Previous Survey}

The patients in the previous survey were 1839 men and 2449 women (no difference in the sex ratio), and their mean age was $68.1 \pm 13.0$ years, ranging from 7 to 102 years. Compared with the previous survey, patients' mean age and the mean number of medications in use were significantly higher in the survey conducted in 2020 ( $\mathrm{P}=0.0108$ and $\mathrm{P}=0.0032$, respectively) (Table 2). The rate of POAG was significantly higher in the 2020 survey than that in the 2016 survey $(\mathrm{P}=0.0222)$, whereas the rate of PACG was significantly higher in the 2016 survey than that in the 2020 survey $(\mathrm{P}=0.0061)$. The rate of patients who had a history of surgery was similar in the two surveys $(\mathrm{P}=0.2479)$; however, the rate of patients who had a history of laser treatment was significantly higher in the 2016 survey than that in the 2020 survey $(\mathrm{P}<0.0001)$.

A comparison of fixed-combination eye drops used in the 2020 and 2016 reports is presented in Figure 3. In the twomedications group, $\mathrm{PG} / \beta$ fixed-combination eye drops were most common, followed by $\mathrm{PG}$ analogs $+\beta(\alpha \beta)$-blockers, in both surveys. The use of $\mathrm{PG} / \beta$ fixed-combination eye drops in this group significantly increased from 2016 (28.7\%) to

Table 2 Comparison of Patients' Characteristics in Previous Study and This Study (2016 and 2020)

\begin{tabular}{|c|c|c|c|}
\hline & 2020 & 2016 & $\mathbf{P}$ \\
\hline Number of patients & 5303 & 4288 & \\
\hline Mean \pm standard deviation age, years & $68.7 \pm 13.1$ & $68.1 \pm 13.0$ & 0.0108 \\
\hline Sex, men:women & 2347:2956 & 1839:2449 & 0.1851 \\
\hline \multirow[t]{7}{*}{ Type of glaucoma } & NTG: 2710 & NTG: 2197 & 0.9019 \\
\hline & POAG: 1638 & POAG: 1232 & 0.0222 \\
\hline & Secondary glaucoma: 435 & Secondary glaucoma: 378 & 0.2853 \\
\hline & Ocular hypertension: 286 & Ocular hypertension: 242 & 0.6205 \\
\hline & PACG: 225 & PACG: 234 & 0.0061 \\
\hline & Infantile glaucoma: 4 & Infantile glaucoma: 5 & 0.5252 \\
\hline & Others: 5 & & \\
\hline \multirow[t]{2}{*}{ History of glaucoma surgery/laser treatment } & Surgery: 366 & Surgery: 270 & 0.2479 \\
\hline & Laser: 220 & Laser: 257 & $<0.0001$ \\
\hline Mean \pm standard deviation number of medications in use & $1.8 \pm 1.3$ & $1.7 \pm 1.2$ & 0.0032 \\
\hline
\end{tabular}

Abbreviations: NTG, normal-tension glaucoma; POAG, primary open-angle glaucoma; PACG, primary angle-closure glaucoma. 


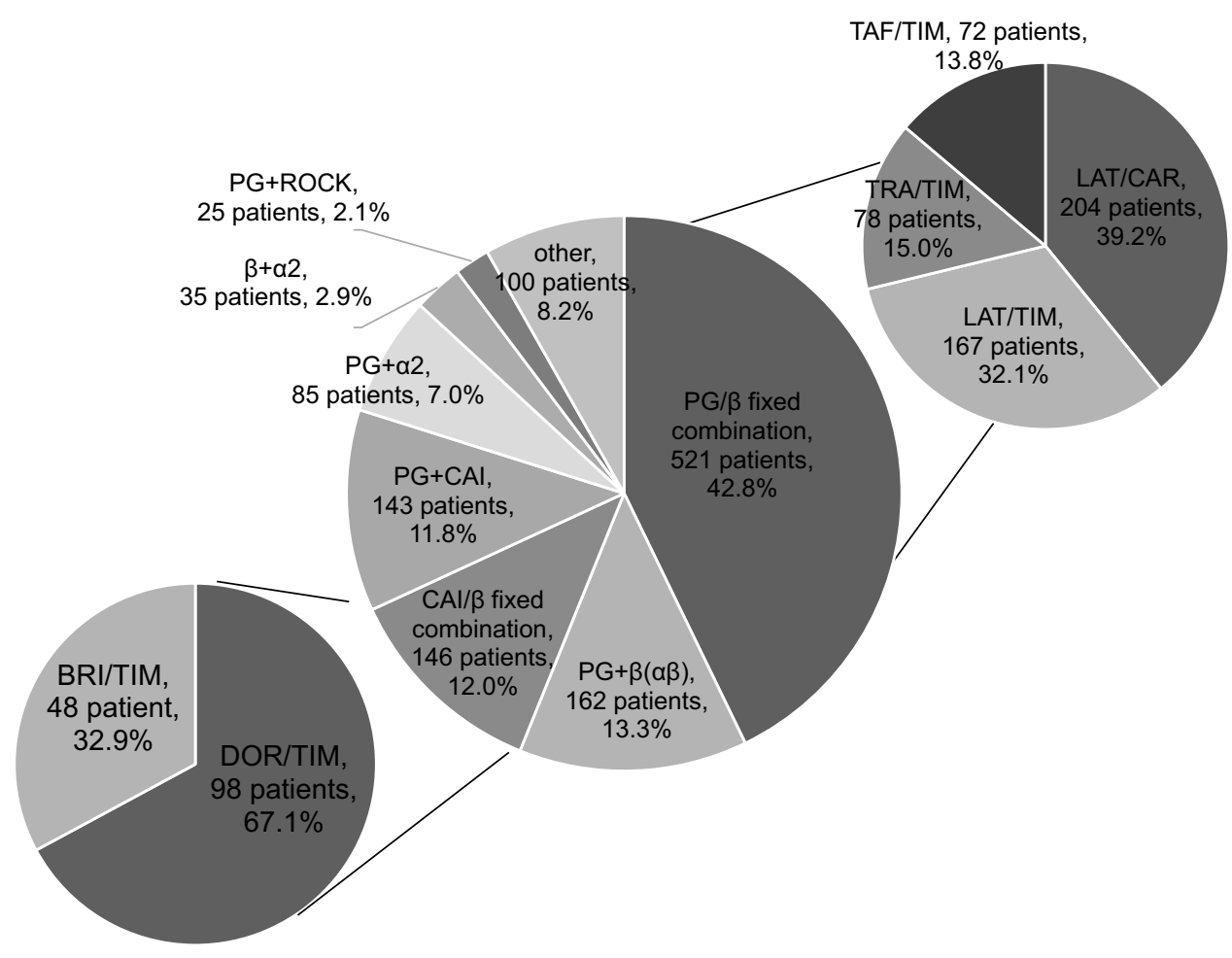

Figure 2 The details of medications used in the two-medications group.

Abbreviations: $\alpha 2, \alpha$-2-adrenergic agonist; $\beta, \beta$-blocker; BRI, brinzolamide; CAI, carbonic anhydrase inhibitor; CAR, carteolol; DOR, dorzolamide; LAT, latanoprost; PG, prostaglandin analog; ROCK, Rho-associated protein kinase; TAF, tafluprost; TIM, timolol; TRA, travoprost.

2020 (42.8\%) $(\mathrm{P}<0.0001)$. There were no differences in the use of $\mathrm{CAI} / \beta$ fixed-combination eye drops between the two studies $(\mathrm{P}=0.1660)$. For $\mathrm{PG} / \beta$ fixed-combination eye drops, there were no differences between the two studies in the use of latanoprost/timolol $(\mathrm{P}=0.1957)$ or tafluprost/timolol $(\mathrm{P}=0.0773)$ fixed-combination eye drops, and the use of travoprost/timolol fixed-combination eye drops decreased $(\mathrm{P}=0.0381)$.

In the three-medications group, the most common combination used in 2016 were $\mathrm{PG}$ analogs $+\mathrm{CAI} / \beta$ fixed-combination eye drops, followed by PG $/ \beta$ fixed-combination eye drops + CAI eye drops and PG analogs $+\beta$-blocker + CAI eye drops. In this survey, the most common combination used was also PG analogs $+\mathrm{CAI} / \beta$ fixed-combination eye drops, followed by PG/ $\beta$ fixed-combination eye drops $+\alpha 2$-agonist and PG $/ \beta$ fixed-combination eye drops + CAI eye drops. The use of PG/ $\beta$ fixedcombination eye drops significantly increased from 2016 (21.7\%) to 2020 (36.2\%) $(\mathrm{P}<0.0001)$.

In the four-medications group, the most common combination used in 2016 was PG analogs $+\mathrm{CAI} / \beta$ fixedcombination eye drops $+\alpha 2$-agonist, followed by PG $/ \beta$ fixed-combination eye drops + CAI eye drops $+\alpha 2$-agonist and $\mathrm{PG}$ analogs $+\mathrm{CAI} / \beta$ fixed-combination eye drops + ROCK inhibitor. In this survey, the most common combination was also PG analogs $+\mathrm{CAI} / \beta$ fixed-combination eye drops $+\alpha 2$-agonist, followed by $\mathrm{PG}$ analogs $+\mathrm{CAI} / \beta$ fixedcombination eye drops + ROCK inhibitor and PG $/ \beta$ fixed-combination eye drops + CAI eye drops $+\alpha 2$-agonist. There was no difference in the use of $\mathrm{PG} / \beta$ and $\mathrm{CAI} / \beta$ fixed-combination eye drops between the previous and current surveys.

In the five-medications group, the prescription patterns and the use of $\mathrm{PG} / \beta$ and $\mathrm{CAI} / \beta$ fixed-combination medications were similar between the previous and current surveys $(\mathrm{PG} / \beta, \mathrm{P}=0.6448 ; \mathrm{CAI} / \beta, \mathrm{P}=0.5941)$.

\section{Use of Latanoprost/Carteolol and Brimonidine/Timolol Fixed-Combination Medication}

The use of latanoprost/carteolol fixed-combination eye drops is shown in Figure 4. In the two-medications group, it was the most commonly used PG/ $\beta$ fixed-combination eye drops. 
Table 3 Medications in Use in the Three-, Four-, Five-, and Six-Medications Groups

\begin{tabular}{|c|c|c|c|c|}
\hline & \multicolumn{2}{|c|}{2020} & \multicolumn{2}{|c|}{2016} \\
\hline & $\mathbf{N}$ & $\%$ & $\mathbf{N}$ & $\%$ \\
\hline \multicolumn{5}{|l|}{ Three-medications group } \\
\hline $\mathrm{CAl} / \beta \mathrm{FC}+\mathrm{PG}$ analogs & 270 & $35.8 \%$ & 236 & $39.5 \%$ \\
\hline $\mathrm{PG} / \beta \mathrm{FC}+\alpha 2$ agonist & 115 & $15.3 \%$ & 51 & $8.5 \%$ \\
\hline PG/ $\beta$ FC + CAI (eye drops) & 110 & $14.6 \%$ & 58 & $9.7 \%$ \\
\hline $\mathrm{CAl} / \beta \mathrm{FC}+\alpha 2$ agonist & 37 & $4.9 \%$ & 17 & $2.8 \%$ \\
\hline Others & 222 & $29.4 \%$ & 236 & $39.5 \%$ \\
\hline \multicolumn{5}{|l|}{ Four-medications group } \\
\hline $\mathrm{CAl} / \beta \mathrm{FC}+\mathrm{PG}$ analogs $+\alpha 2$ agonist & 156 & $39.9 \%$ & 120 & $43.3 \%$ \\
\hline $\mathrm{CAl} / \beta \mathrm{FC}+\mathrm{PG}$ analogs $+\mathrm{ROCK}$ inhibitor & 53 & $13.6 \%$ & 27 & $9.7 \%$ \\
\hline$P G / \beta F C+C A I$ (eye drops) $+\alpha 2$ agonist & 40 & $10.2 \%$ & 29 & $10.5 \%$ \\
\hline Others & 142 & $36.3 \%$ & 101 & $36.5 \%$ \\
\hline \multicolumn{5}{|l|}{ Five-medications group } \\
\hline $\mathrm{CAl} / \beta \mathrm{FC}+\mathrm{PG}$ analogs $+\alpha 2$ agonist $+\mathrm{ROCK}$ inhibitor & 91 & $56.9 \%$ & 39 & $39.4 \%$ \\
\hline $\mathrm{PG} / \beta \mathrm{FC}+\mathrm{CAl}$ (eye drops) $+\alpha 2$ agonist + ROCK inhibitor & 32 & $20.0 \%$ & 10 & $10.1 \%$ \\
\hline Others & 37 & $23.1 \%$ & 50 & $50.5 \%$ \\
\hline \multicolumn{5}{|l|}{ Six-medications group } \\
\hline $\mathrm{CAl} / \beta \mathrm{FC}+\mathrm{PG}$ analogs $+\alpha 2$ agonist $+\mathrm{ROCK}$ inhibitor $+\mathrm{CAl}$ (oral) & 18 & $52.9 \%$ & 13 & $54.2 \%$ \\
\hline $\mathrm{PG} / \beta \mathrm{FC}+\mathrm{CAl}$ (eye drops) $+\mathrm{CAl}$ (oral) $+\alpha 2$ agonist $+\mathrm{ROCK}$ inhibitor & 3 & $8.8 \%$ & I & $4.2 \%$ \\
\hline Others & 13 & $38.2 \%$ & 10 & $41.7 \%$ \\
\hline
\end{tabular}

Abbreviations: $\alpha 2$ agonist, $\alpha$-2-adrenergic agonist; $\beta$, $\beta$-blocker; CAl, carbonic anhydrase inhibitor; FC, fixed combination; PG, prostaglandin analog; ROCK, Rho-associated protein kinase.

\section{Discussion}

In this study, we investigated the use of fixed-combination eye drops. The types and numbers of such eye drops have increased over the years. Therefore, we expected the distribution of their use to change. The various fixed-combination eye drops have different efficacies in lowering intraocular pressure (IOP) and pose risks for different adverse reactions, ${ }^{8-10}$ and ophthalmologists select such medications based on these factors. According to the 2020 survey, fixed-combination medications were used in $55.6 \%$ patients in the two-medications group, $79.8 \%$ in the three-medications group, $84.9 \%$ in the fourmedications group, $91.3 \%$ in the five-medications group, and $94.1 \%$ in the six-medications group. Thus, the proportion of fixed-combination eye drops used increased from 2016 to 2020. There was a significant increase in the number of medications in use per patient compared to that in the previous survey. Two new fixed-combination eye drops became available in the time between the surveys. The number of bottles used per patient (1.5 \pm 1.0 bottles in the previous survey and $1.4 \pm 1.0$ bottles in the current survey) were equivalent between the surveys $(\mathrm{P}=0.4444)$. Therefore, the increase in the number of medications used per patient may have been due to the increased use of new fixed-combination products.

We observed certain changes in the use of fixed-combination eye drops from the 2016 survey $^{5}$ to the present survey. In the two-medications group, there was a statistically significant increase in the use of $\mathrm{PG} / \beta$ fixed-combination eye drops. The use of $C A I / \beta$ fixed-combination eye drops was the same between the studies. Among the PG/ $\beta$ fixedcombination eye drops, the use of latanoprost/timolol and tafluprost/timolol was the same between the studies. The use of travoprost/timolol fixed-combination eye drops decreased. Latanoprost/carteolol fixed-combination eye drops, which were not available during the 2016 survey, were used by 324 patients $(6.1 \%)$ overall, according to the 2020 survey. They were the most commonly used PG/ $\beta$ fixed-combination eye drops. This may be because carteolol has IOP-lowering effects equivalent to that of timolol with the benefit of being safer; ${ }^{11,12}$ the same is true of latanoprost/carteolol in comparison to latanoprost/timolol. ${ }^{13}$

In the four- and five-medications groups, the use of both $\mathrm{PG} / \beta$ and $\mathrm{CAI} / \beta$ fixed-combination eye drops were the same in 2020 as in $2016 .{ }^{5}$ The increase in the use of PG/ $\beta$ fixed-combination eye drops in the two- and three-medications groups in this study was influenced by the use of latanoprost/carteolol fixed-combination eye drops. As additional 


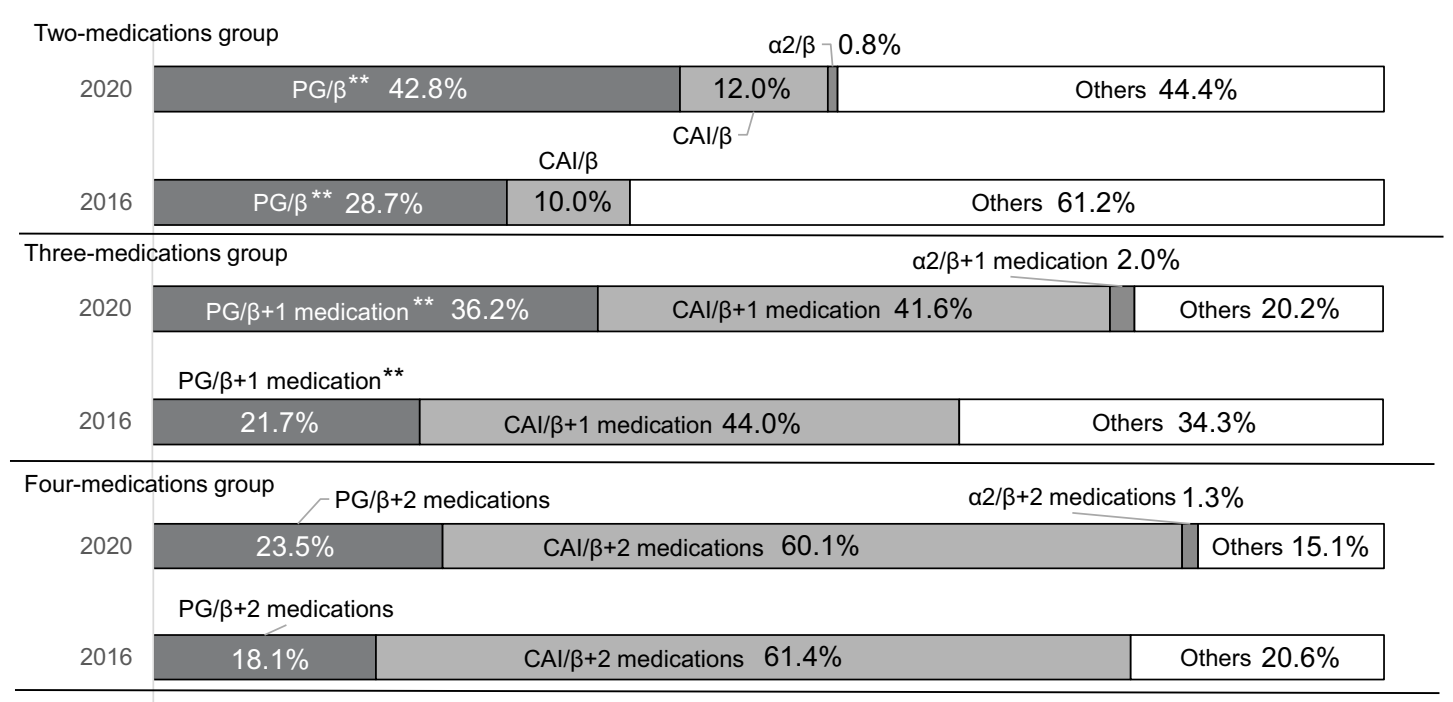

Five-medications group

\begin{tabular}{|c|c|c|c|}
\hline \multirow[b]{2}{*}{2020} & \multicolumn{2}{|c|}{$P G / \beta+3$ medications } & $\alpha 2 / \beta+3$ medications $2.5 \%$ \\
\hline & $23.1 \%$ & $\mathrm{CAl} / \beta+3$ medications $65.6 \%$ & $8.8 \%$ \\
\hline & \multicolumn{3}{|c|}{$P G / \beta+3$ medications } \\
\hline 2016 & $20.2 \%$ & $\mathrm{CAl} / \beta+3$ medications $61.6 \%$ & Others $18.2 \%$ \\
\hline
\end{tabular}

Figure 3 Comparison of fixed-combination medications used in the 2020 and 2016 surveys. ${ }^{* *} p<0.0001\left(\chi^{2}\right.$ test).

Abbreviations: $\alpha 2, \alpha$-2-adrenergic agonist; $\beta, \beta$-blocker; CAl, carbonic anhydrase inhibitor; PG, prostaglandin analog.

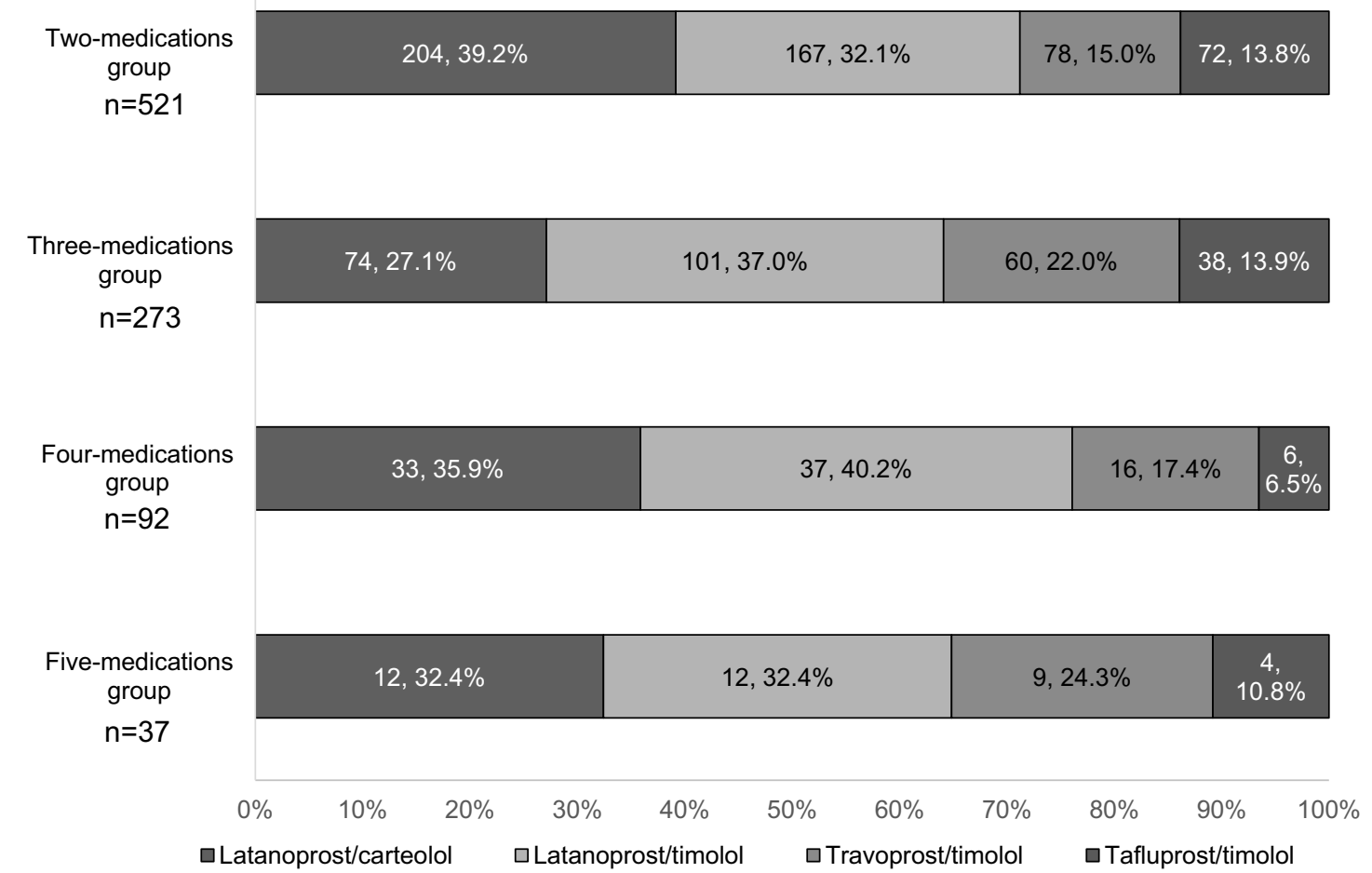

Figure 4 Use of different types of PG/ $\beta$ fixed-combination medications.

Abbreviations: $\beta, \beta$-blocker; PG, prostaglandin analog. 
medications are added for patients currently using two or three medications, $\mathrm{PG} / \beta$ fixed-combination eye drops are expected to increase in patients using four or five medications.

In this study, $\alpha 2 / \beta$ fixed-combination eye drops had been available for only three months at the time of the survey, which explains why few patients used it. Brimonidine/timolol fixed-combination eye drops have been available in Korea longer than in Japan, and their efficacy and safety have been reported. ${ }^{14}$ However, the brimonidine in the Japanese version of the eye drops is a formulation of $0.1 \%$, which differs from the formulation of $0.2 \%$ in the Korean version. In this study, the most common concomitant medications with brimonidine/timolol fixed-combination eye drops in the three-medications group were PG analogs, used by $12(80.0 \%)$ patients. This may be because PG is the first-choice eye drop for the treatment of glaucoma. The use of brimonidine/timolol fixed-combination eye drops is expected to increase over time.

There are several limitations in this study. First, since the answers to this survey were based on prescriptions, it is unclear to what extent patients adhered to the prescribed medications. Second, the data included both branded and generic products, and it is not clear which the patients were using. Third, as the number of patients handled by different doctors varies, there is a possibility of bias toward prescriptions made by doctors with many patients. Fourth, the cooperating facilities in this survey were facilities that the physicians independent from the Inouye Eye Hospital group were belonging or facilities collaborating with it. For this reason, their prescription patterns may be similar. Facilities from all over Japan participated in the survey; however, the Kanto region, where Inoue Eye Hospital and Nishikasai Inoue Eye Hospital are located, contained 79.5\% (62 of 78) of them. Fifth, the participants were not necessarily the same in the previous and current surveys. This is because, in order to investigate the current state of fixed-combination eyedrop use, a larger number of cases was collected in this study than in the previous study. However, considering the aforementioned bias, it is possible that even more reliable results may be obtained for the comparison between surveys if the number of cases per physician and institution are matched.

\section{Conclusion}

In this survey of patients with glaucoma, many patients used fixed-combination eye drops; PG/ $\beta$ fixed-combination eye drops were the most common type in the two-medications group, and $\mathrm{CAI} / \beta$ in the groups of patients using three or more medications. Compared to the 2016 survey, ${ }^{5}$ there was a statistically significant increase in the use of PG/ $\beta$ fixedcombination eye drops in the two- and three-medications groups, and there was no difference in the use of PG/ $\beta$ and CAI/ $\beta$ fixed-combination eye drops in the four- and five-medications groups. We expect that fixed-combination eye drops will be used increasingly by patients who need multiple eye medications. Moreover, we expect that the use of these fixedcombination eye drops will serve as a prescription guide for clinicians and as a reference for the development of new fixed-combination eye drops, indicating which products are most likely to be used.

\section{Abbreviations}

$\alpha 2 / \beta, \alpha$-2-adrenergic agonist/ $\beta$-blocker; CAI $/ \beta$, carbonic anhydrase inhibitor/ $\beta$-blocker; IOP, intraocular pressure; PG/ $\beta$, prostaglandin analog/ $\beta$-blocker; ROCK, Rho-associated protein kinase.

\section{Data Sharing Statement}

The participants' data that support the findings of this study are available for five years after publication from the corresponding author, Kenji Inoue, upon reasonable request.

\section{Acknowledgments}

We would like to thank the doctors from the 78 institutions for collecting the data for this survey.

\section{Funding}

There is no funding to report. 


\section{Disclosure}

K. Inoue reports grants from Teijin, Otsuka, and Wakamoto; and lecture fees from Otsuka, HOYA, Pfizer, Senju, Santen, Allergan, Novartis, and Carl Zeiss Meditec. S. Kunimatsu-Sanuki reports lecture fees from Santen, Novartis, Alcon, Sucampo, Senju, Otsuka, Pfizer, and Kowa. K. Ishida reports lecture fees from Alcon, Pfizer, Santen, Senju, Otsuka, Kowa, Sucampo, GlaxoSmithKline, JFC Sales Plan, Japan Ophthalmic Instruments Association, Novartis, Wakamoto, Allergan, Bayer Yakuhin, and Nitto Medic. G. Tomita reports grants from Pfizer, Santen, Senju, Eisai, Handaya, Kowa, and Otsuka; and lecture fees from Santen, Senju, Allergan Japan, and TOPCON. R. Komori reports no conflicts of interest in this work. The authors report no other conflicts of interest in this work.

\section{References}

1. The Japan Glaucoma Society. Guidelines for Glaucoma. 4th ed. Nippon Ganka Gakkai Zasshi. 2018;122:5-53. Japanese.

2. Djafari F, Lesk MR, Harasymowycz PJ, Desjardins D, Lachaine J. Determinants of adherence to glaucoma medical therapy in a long-term patient population. J Glaucoma. 2009;18(3):238-243. doi:10.1097/IJG.0b013e3181815421

3. Nakai Y, Inoue K, Moriyama R, Wakakura M, Inoue J, Tomita G. Current status of glaucoma therapy at private practices and a private ophthalmology hospital. Atarashii Ganka. 2008;25:1581-1585. Japanese.

4. Nagai M, Higa R, Shiokawa M, Inoue K, Ishida K, Tomita G. Current status of therapy for glaucoma at multiple ophthalmic institutions in 2016. Atarashii Ganka. 2017;34:1035-1041. Japanese.

5. Inoue K, Nagai M, Arai Y, Shiokawa M, Ishida K, Tomita G. Current status of therapy for glaucoma at multiple ophthalmic institutions in 2016: fixed combination eye drops. Rinsho Ganka. 2017;71:1743-1754. Japanese.

6. Shiokawa M, Inoue K, Tomita G. Current status of glaucoma therapy at private practices and private ophthalmology hospital in 2012. Atarashii Ganka. 2013;30:851-856. Japanese.

7. Kuroda A, Inoue K, Inoue J, Kunimatsu-Sanuki S, Ishida K, Tomita G. Multi-institutional survey for glaucoma in 2020-drug therapy. Rinsho Ganka. 2021;75:377-385. Japanese.

8. Joh HJ, Jin SW. Comparison of different combinations of maximum medical therapy for lowering intraocular pressure in primary open angle glaucoma: 12-month retrospective consecutive case series. Jpn J Ophthalmol. 2019;63(4):322-327. doi:10.1007/s10384-019-00673-8

9. Hashimoto Y, Kitamoto K, Aihara M, Usui T. Toxicity profiles of fixed-combination eye drops for glaucoma therapy using cultivated human corneal epithelial sheets. Jpn J Ophthalmol. 2020;64(3):304-311. doi:10.1007/s10384-020-00742-3

10. Xing Y, Zhu L, Zhang K, Huang S. The efficacy of the fixed combination of latanoprost and timolol versus other fixed combinations for primary open-angle glaucoma and ocular hypertension: a systematic review and meta-analysis. PLoS One. 2020;15(2):e0229682. doi:10.1371/journal. pone. 0229682

11. Netland PA, Weiss HS, Stewart WC, Cohen JS, Nussbaum LL; Night Study Group. Cardiovascular effects of topical carteolol hydrochloride and timolol maleate in patients with ocular hypertension and primary open-angle glaucoma. Am J Ophthalmol. 1997;123(4):465-477. doi:10.1016/ s0002-9394(14)70172-2

12. Stewart WC, Cohen JS, Netland PA, Weiss H, Nussbaum LL; Nocturnal Investigation of Glaucoma Hemodynamics Trial Study Group. Efficacy of carteolol hydrochloride $1 \%$ vs timolol maleate $0.5 \%$ in patients with increased intraocular pressure. Am J Ophthalmol. 1997;124(4):498-505. doi:10.1016/s0002-9394(14)70865-7

13. Saito Y, Kizaki J, Wada Y, Shibasaki Y, Kishimoto N, Aihara M. Comparison of the 24-h efficacy and safety of fixed combination carteolol/ latanoprost and timolol/latanoprost in patients with primary open-angle glaucoma and ocular hypertension: a prospective crossover study. Jpn J Ophthalmol. 2021;65(5):598-607. doi:10.1007/s10384-021-00856-2

14. Park SW, Kim JM, Lee JW, Maglambayan J, Simonyi S, Park KH. Efficacy and safety of fixed-combination brimonidine tartrate/timolol maleate in primary open-angle glaucoma, including normal-tension glaucoma. Jpn J Ophthalmol. 2021;65(2):295-305. doi:10.1007/s10384-020-00796-3

Clinical Ophthalmology

Dovepress

\section{Publish your work in this journal}

Clinical Ophthalmology is an international, peer-reviewed journal covering all subspecialties within ophthalmology. Key topics include: Optometry; Visual science; Pharmacology and drug therapy in eye diseases; Basic Sciences; Primary and Secondary eye care; Patient Safety and Quality of Care Improvements. This journal is indexed on PubMed Central and CAS, and is the official journal of The Society of Clinical Ophthalmology (SCO). The manuscript management system is completely online and includes a very quick and fair peer-review system, which is all easy to use. Visit http://www. dovepress.com/testimonials.php to read real quotes from published authors.

Submit your manuscript here: https://www.dovepress.com/clinical-ophthalmology-journal 